\title{
NOVEL CFD ANALYSIS ON HEAT TRANSFER CHARACTERISTICS OF NANO COOLANTS FOR AUTOMOBILE RADIATORS
}

\section{VIDYA. CH ${ }^{1}$, G. RAVI KIRAN SASTRY ${ }^{2}$, P. PHANI PRASANTHI ${ }^{3}$ \& SNIGDHA SURAPANENI ${ }^{4}$}

${ }^{I}$ Scholar, National Institute of Technology Andhra Pradesh, India

2Professor, Department of Mechanical Engineering, National Institute of Technology

${ }^{3}$ Associate Professor, Department of Mechanical Engineering, P.V.P.Siddhartha Institute of Technology, Vijayawada, India

${ }^{4}$ Assistant Professor, Department of Mechanical Engineering, LBRCE, Andhra Pradesh, India

\begin{abstract}
The research on the heat transfer efficiency of an automobile radiator is gaining more interest not only to increase automobile efficiency and also to increase the fuel economy. In this research work, the radiator heat transfer efficiency is evaluated by using the nano-based coolants. For the nano-based coolants, $\mathrm{Al}_{2} \mathrm{O}_{3}$ and $\mathrm{CuO}$ nanoparticles are used and these particles are mixed with water and the resulting nanofluids influence on the radiator heat transfer. The heat transfer analysis models are created in Ansys fluent solver. By varying the different concentration of nanoparticles in the base fluid, different radiators made with steel, copper, aluminium are evaluated for the performance of the radiator in terms of Nusselt number, thermal conductivity, and rate of heat transfer.

KEYWORDS: CFD Analysis, Aluminium \& Nanoparticles
\end{abstract}

Received: May 25, 2020; Accepted: Jun 15, 2020; Published: Jun 30, 2020; Paper Id.: IJMPERDJUN2020172

\section{INTRODUCTION}

The performance of any automobile depends on many factors and one among the factors are cooling systems. The efficiency of the heat rejection system of an internal combustion engine is directly related to the performance of the automobile radiator. The cooling system efficiency depends on the type of coolant used and the shape of the fins fabricated on the cooling system. In the present decade, nanofluids are being used to enhance the performance of the cooling systems. Nanomaterial has a high surface area; this feature further enhances the heat exchange capabilities. A clear understanding of heat exchange properties is required to suggest or to replace the already used fluids as coolants. Since recent decades considerable research efforts have been contributed towards engine cooling system of the automotive sector. A study performed by Ali et al. [1] reported that changing extended surface geometry as well as flow channels of the radiator has saturated.

Extensive research has been conducted towards numerical study with variation in fin geometry of plate as well as shell and tube type heat exchangers [2-4].Low thermal conductivity of the cooling agents has become the greatest limitation to the improvement in the heat exchange capability of conventional radiators. R. N. Vinod et al [5] have studied the influence of water and anti-freezing agents as heat transfer medium. J. Lv et al [6] had conducted a numerical analysis to study the effect of $\mathrm{CuO}$ nanoparticles dispersion on the heat absorption rate of IC engine coolant up to the 5\% volume fraction using Star-CD module of CFD and reported 46\% enhancement in heat transfer coefficient. 
Application of $\mathrm{Al}_{2} \mathrm{O}_{3}$, as well as CuONano fluids in the performance improvement of flat tubes, attempted numerically by Vajjha et al [7] using fluent software. The study extended up to Revalue of 2000 and the results reported that up to $94 \%$ improvement in heat transfer coefficient with $10 \%$ volume fraction of $\mathrm{Al} 2 \mathrm{O} 3$, whereas $6 \%$ of $\mathrm{CuO}$ led $89 \%$ enhancement in comparison to the base fluid. Huminic et al [8] conducted a novel computational study on the flattened tube containing $4 \%$ volume fraction of $\mathrm{CuO}$ nanoparticles in ethylene glycol for a Reynolds number value 125, the numerical results indicated an enhancement of around $82 \%$ in heat transfer rate. In another study by Vajjha et al [9], for a Re value of 5500, enhancement rates of $36.6 \%$ and $49.7 \%$ arrived for a volume fraction of $3 \%$ with $\mathrm{Al} 2 \mathrm{O} 3$ and $\mathrm{CuO}$ respectively.

Huminic and Huminic [10] conducted CFD analysis to compare the influence of the geometry of the flow tube on the convective heat transfer coefficient value using $\mathrm{CuO} / \mathrm{EG}$ nanofluid. The analysis reported higher improvement with a flat tube in comparison to circular as well as an elliptical cross-section. P. Vivekh et al [11] modelled dehumidification capacity of a desiccant coated heat exchanger using CFD platform to develop a new mathematical model. Validation of the corresponding modelreported a discrepancy of $14 \%$ with respect to experimental observations.

Yuwen You et al [12] adopted an indirect evaporative cooling approach to analyze the influence of inlet temperature, relative humidity, mass flow rate as well as channel height on the heat transfer capacity. Validation of the model concluded that better condensation with higher inlet air temperature along with high relative humidity. Small duct height leads to better heat exchange performance. Pantzali et al. [13] performed a numerical and experimental study of the influence of nanofluids on the performance of a miniature plate heat exchanger and concluded that, for a given heat duty, the required flow rate of nanofluid was obtained to be lower than that of water causing lower pressure drop which implied reduction in pumping power.

P.C. Mahesh Kumar et al [14] investigated numerically the pressure drop characteristics of helical coil heat exchanger handling $\mathrm{Al}_{2} \mathrm{O}_{3}$ nanofluid operating in the Dean number range of 1650 to 2650. The study reported good agreement between experimental and numerical results water nanofluid, R.V.M. Raja et al. [15] conducted a numerical

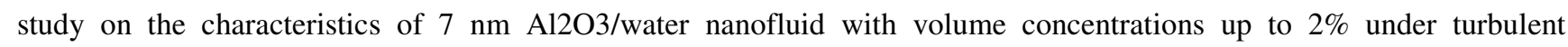
conditions.

Hussein et al. [16] studied the rate of enhancement of heat transfer using $\mathrm{TiO} 2$ and $\mathrm{SiO} 2$ nanoparticles suspended in pure water under laminar flow conditions. Their results showed that the Nusselt number increased as the volume flow rate, inlet temperature and nanofluid volume concentration increased. Asmaie et al. [17] modelled thermal performance of $\mathrm{CuO}-\mathrm{H} 2 \mathrm{O}$ nanofluid in thermo siphon heat pipe using Computational Fluid Dynamics. Their analysis reported that the heat flux varies directly proportional with the volume fraction of nanoparticles, whereas the wall temperature of the heat pipe observed moving in the opposite direction.

\section{GEOMETRICAL MODELING}

A car radiator is modelled in Ansys software with 2 flat tubes and these two flat tubes are connected by rectangular geometry fins as shown in the figure 1 . 


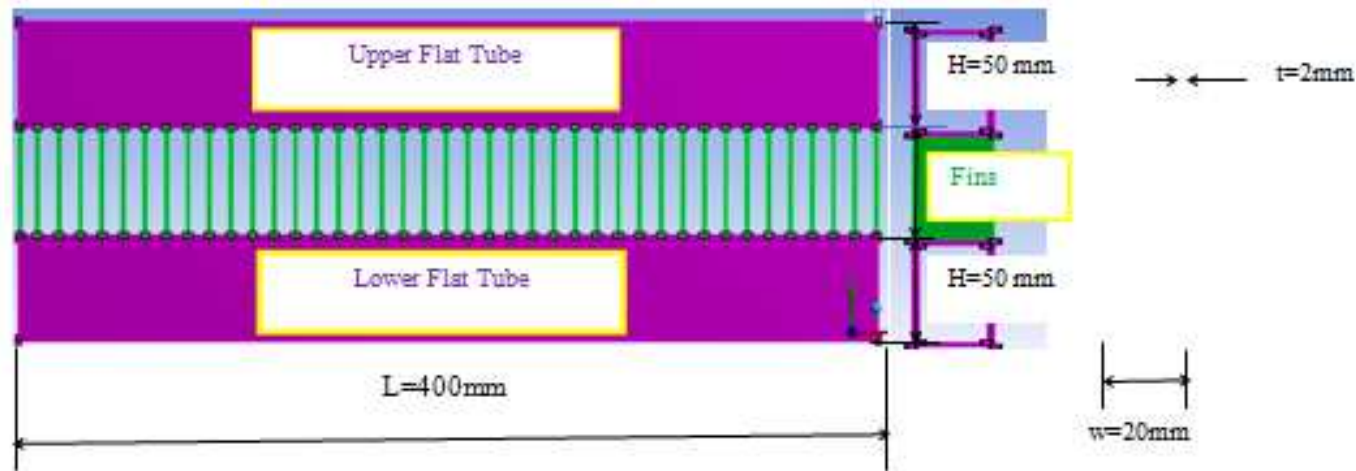

Figure 1: Geometrical Model of a Flat Tube with Flat Fins.

Water is passing through the two flat tubes at different boundary conditions and the fins are used to decrease the temperature of the water passing through tubes by exposing to the ambient air. The tube length is $400 \mathrm{~mm}$, the height is $50 \mathrm{~mm}$ and the thickness of the tube is $2 \mathrm{~mm}$. The distance between the upper water tube and the lower water tube is maintained of 50mm. In this gap, fins are modelled throughout the length of the flat tubeby maintaining a gap of $10 \mathrm{~mm}$ between two consecutive fins. The finite element meshes on the flat tubes with fins are shown in figure 2 . The geometry of the present problem is modelled in Ansys design modeller.

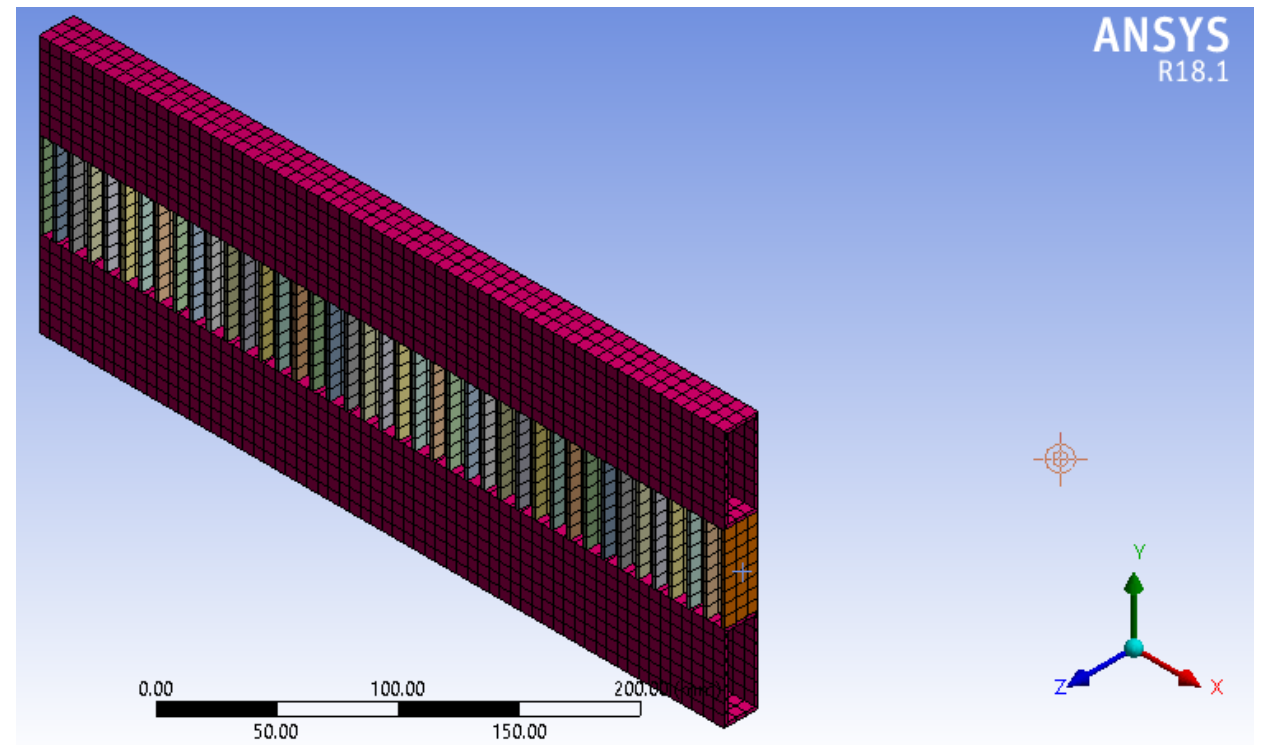

Figure 2: Finite Element Mesh of Flat Tubes with Fins.

\section{Finite Element Modeling}

For the present analysis, different types of materials are considered for the analysis. Copper, aluminium, steel and bronze type of tubes and fins are considered for the analysis. The finite element mesh convergence test is performed to perform the present study. The Finite element model is shown in the figure 2.

\section{Loading and Boundary Conditions}

The water is entering to the tube at a different velocity of $0.0387 \mathrm{~m} / \mathrm{s}, 0.0516 \mathrm{~m} / \mathrm{s}, 0.0645 \mathrm{~m} / \mathrm{s}$ and $0.077 \mathrm{~m} / \mathrm{s}$ which are corresponding to the volumetric flow rate of $3 \mathrm{~L} / \mathrm{min}, 4 \mathrm{~L} / \mathrm{min}, 5 \mathrm{~L} / \mathrm{min}$ and $6 \mathrm{~L} / \mathrm{min}$. The flat tube wall is subjected to convection heat transfer coefficient of $10 \mathrm{w} / \mathrm{m}^{2} \mathrm{~K}$ and ambient air temperature is at $35^{\circ} \mathrm{c}$. The ambient air is allowed to rush 
across the fins with a velocity of $0.1 \mathrm{~m} / \mathrm{s}$.

\section{Fluid Properties}

The thermo physical properties of the base fluid, $\mathrm{Al}_{2} \mathrm{O}_{3}$ nanofluid, $\mathrm{CuO}$ based nanofluid properties are obtained from open literature. These fluids are passed through the flat tube by providing above loading and boundary conditions. The heat transfer performance, Prandtl number, outlet velocity, Renolds number, Nusselt number and heat transfer coefficient are evaluated for different concentration of nanoparticles.
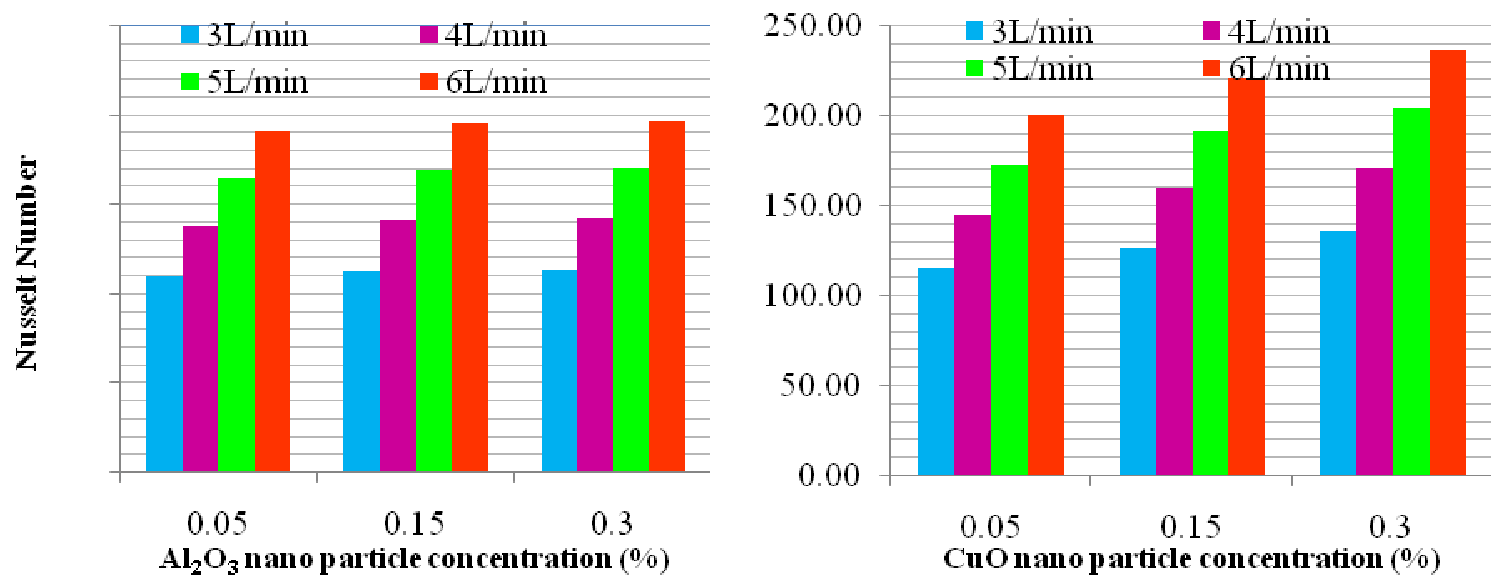

Figure 3: Variation of Nusselt Number of A12O3 and CuOnano Concentration in the Water.
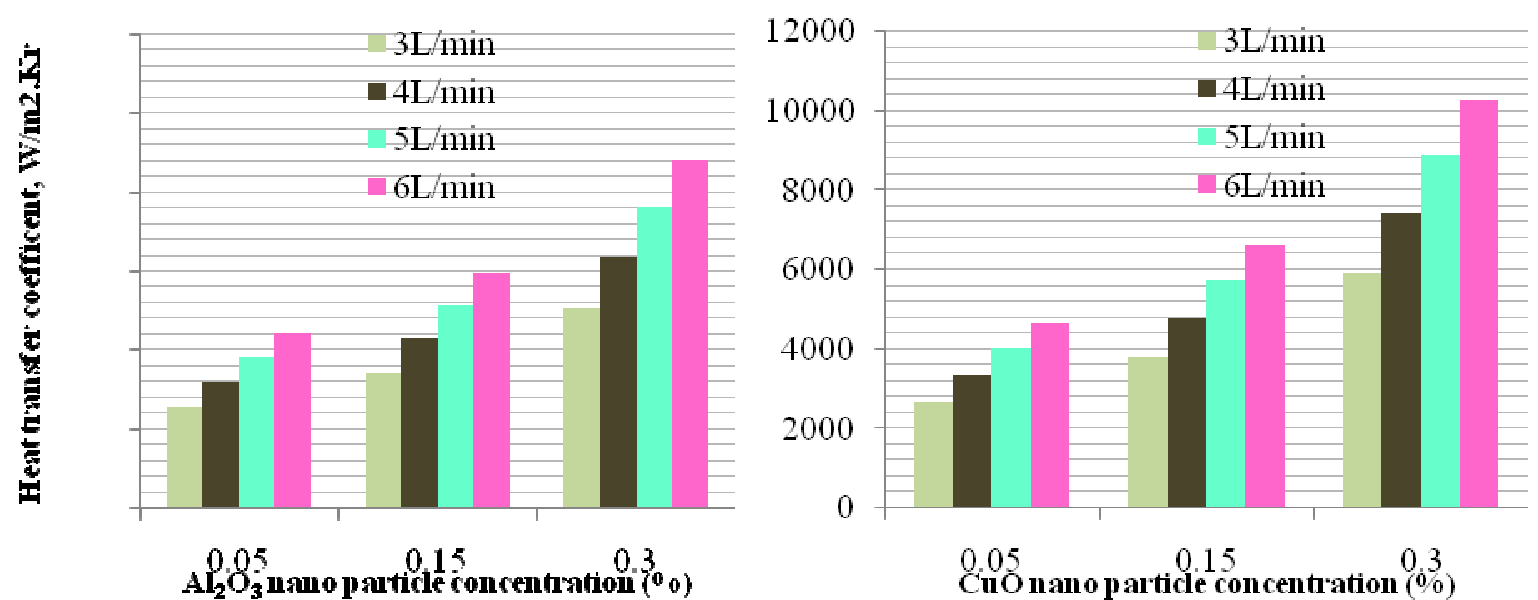

Figure 4: Variation of Heat Transfer Coefficient of $\mathrm{Al}_{2} \mathrm{O}_{3}$ and CuOnano Concentration in the Water. 


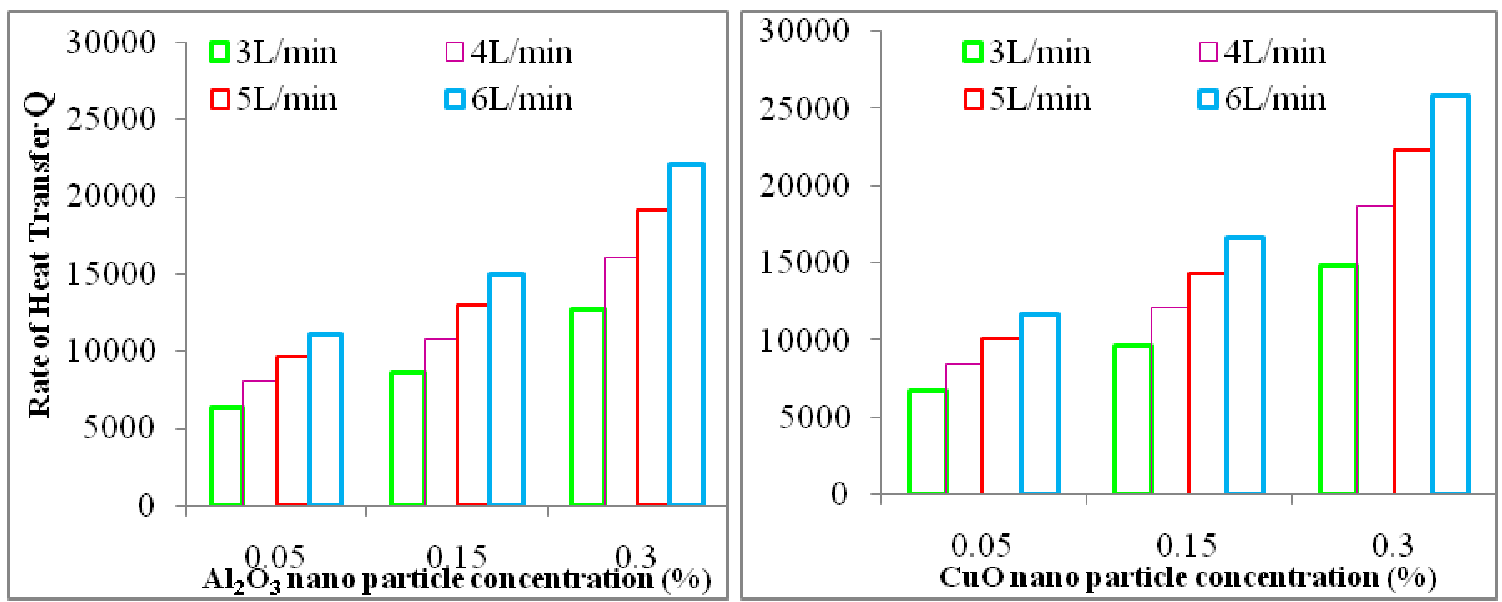

Figure 5: Variation of Rate of Heat Transfer Coefficient of $\mathrm{Al}_{2} \mathrm{O}_{3}$ and CuOnano Concentration in the Water.

Figure 3 shows the variation of Nusselt number of two different nanofluids at different flow rates of coolant. Two types of nanopowder mixed coolants such as $\mathrm{Al}_{2} \mathrm{O}_{3}$ and $\mathrm{CuO}$ nanoparticle mixed base water is supplied to thetubes by changing different flow rates of $3 \mathrm{~L} / \mathrm{min}, 4 \mathrm{~L} / \mathrm{min}, 5 \mathrm{~L} / \mathrm{min}$ and $6 \mathrm{~L} / \mathrm{min}$. The Nusselt number is increasing with the increase in the flow rate and this number is more for $\mathrm{CuO}$ nanoparticle mixed coolant compared to $\mathrm{Al}_{2} \mathrm{O}_{3}$ nanoparticle mixed coolant. This is due to the reason that, the Nusselt number depends on the density of the nanofluid and by the addition of nanoparticles such as $\mathrm{Al}_{2} \mathrm{O}_{3}$ and $\mathrm{CuO}$ the density of the coolant is increased and compared to $\mathrm{Al}_{2} \mathrm{O}_{3}$ nanofluid, the $\mathrm{CuOnanofluid} \mathrm{density} \mathrm{is} \mathrm{more,} \mathrm{as} \mathrm{a} \mathrm{result,} \mathrm{the} \mathrm{Nusselt} \mathrm{number} \mathrm{is} \mathrm{more} \mathrm{for} \mathrm{CuO}$ mixed nanofluids.

The heat transfer coefficient of the $\mathrm{Al}_{2} \mathrm{O}_{3}$ and $\mathrm{CuOnanofluids}$ are identified for flat tubes with rectangular fins arrangement of the problem considered for the present study. For the same rate of fluid flow, the heat transfer coefficient is more for $\mathrm{CuO}$ based nanofluids and the heat transfer coefficient increase with the increasing the flow rate of coolant. In this case, thermal conductivity and density of coolant play a vital role and these two values made the CuO based nanofluid best compared to $\mathrm{Al}_{2} \mathrm{O}_{3}$ mixed fluid as presented in figure 4 .

The rate of heat transfer $(\mathrm{Q})$ is computed from the FE results. The results show that the heat transfer rate is influenced by the rate of flow, temperature drop, specific heat capacity. With the increment of flow rate, the rate of heat transfer is increased in both nano coolants. Particularly, the heat transfer is more for $\mathrm{CuO}$ based nanofluids at a higher flow rate of $6 \mathrm{~L} / \mathrm{min}$ and a higher concentration of nanoparticles as reported in figure 5.

Temperature as well as pressure variation contours are presented in figure $6-9$. 


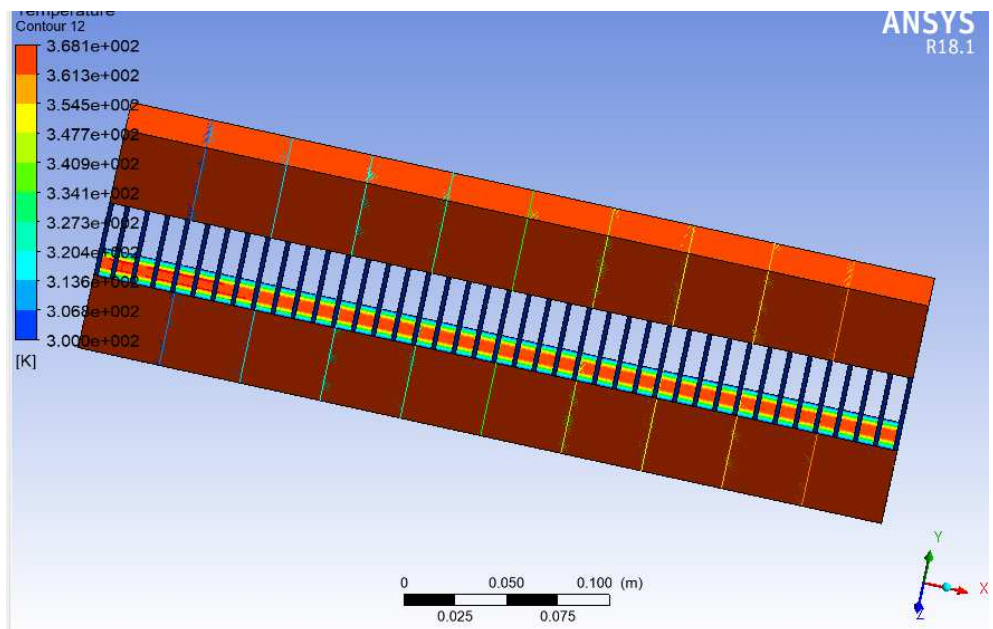

Figure 6: Temperature Contour of Flat Tube and Fins with 0.3\% Cuonanofluid.

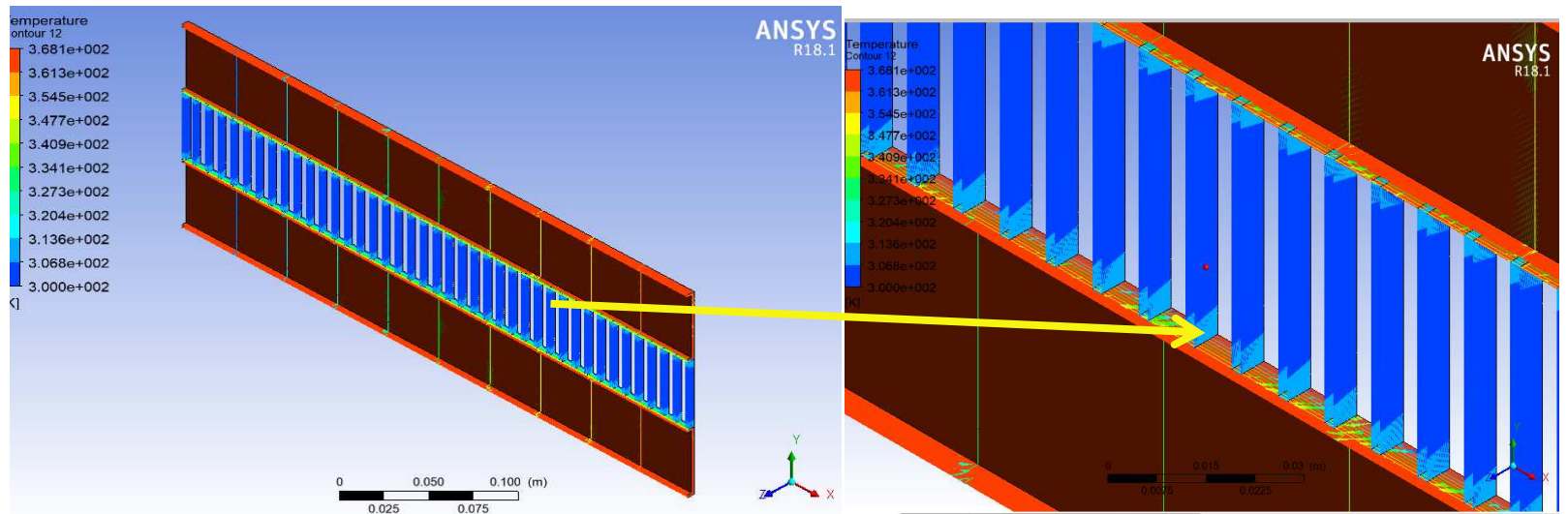

Figure 7: Temperature Contour at the Center Region of Flat Tubes with $0.3 \%$ Cuonanofluid.

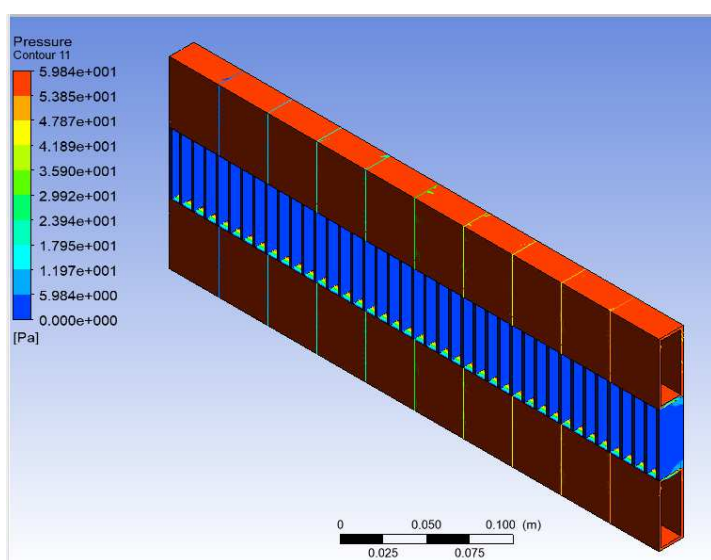

Figure 8: Pressure Contour at $0.3 \% \mathrm{Al}_{2} \mathrm{O}_{3}$ nanofluid.

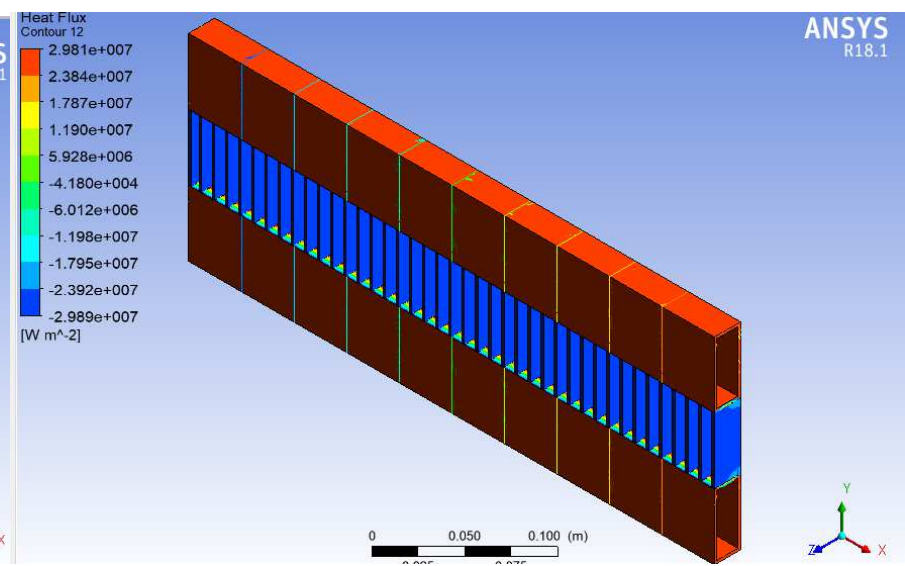

Figure 9: Pressure Contour at $0.3 \%$ CuOnanofluid.

\section{CONCLUSIONS}

The behaviour of Nano fluid mixed coolant while using in the flat tube heat exchanger is analyzed in terms of heat transfer characteristics. $\mathrm{Al}_{2} \mathrm{O}_{3}$ and Cuo based nanofluids performance is compared to each other and base fluid. Hear transfer behaviour of two different nanofluidsare analyzed by comparing Nusselt number, heat transfer coefficient and rate of heat transfer $(\mathrm{Q})$. Compared to ordinary base fluid, the Nusselt number of $\mathrm{Al}_{2} \mathrm{O}_{3}$ and $\mathrm{CuO}$ based nanofluid is more and the flow 
rate has a significant effect on the same number. Compared to $\mathrm{Al}_{2} \mathrm{O}_{3}, \mathrm{CuO}$ based nanofluid showed more Nusselt number particularly at a higher flow rate of $6 \mathrm{~L} / \mathrm{min}$. here the concentration and flow rate of $\mathrm{CuO}$ are the contributing factors for better Nusselt number.

Heat transfer coefficient and rate of heat transfer also predicted for base fluid, $\mathrm{CuO}$ mixed nanofluid and $\mathrm{Al}_{2} \mathrm{O}_{3}$ nanofluids. Compared to pure base fluid, the coefficient of heat transfer and the rate of heat transfer is more for nano mixed fluids at higher concentration and higher flow rates.

\section{REFERENCES}

1. M. Ali, A.M. El-Leathy, Z. Al-Sofyany, The effect of nanofluid concentration on the cooling system of vehicles radiator, Adv. Mech. Eng. 6 (2015), pp. 962510-962510.

2. B. Sahin, A. Demir, Performance analysis of a heat exchanger having perforated square fins, Appl. Therm. Eng. 28 (2008) 621-632.

3. Z. Zhnegguo, X. Tao, F. Xiaoming, Experimental study on heat transfer enhancement of a helically baffled heat exchanger combined with three dimensional finned tubes, Appl. Therm. Eng. 24 (2004) 2293-2300.

4. R.N. Vinod, M. Angadi, O.D. Hebbal, CFD analysis of heat transfer enhancement of a car radiator using nanofluid as a coolant, Int. J. Eng. Res. Technol. (IJERT) 3 (2014) 6.

5. J. Lv, L. Zhou, M. Bai, J.W. Liu, Z. Xu, Numerical simulation of the improvement to the heat transfer within the internal combustion engine by the application of nanofluids, J. Enhanc. Heat Transfer 17 (2010) 93-109.

6. R.S. Vajjha, D.K. Das, P.K. Namburu, Numerical study of fluid dynamic and heat transfer performance of Al2O3 and CuOnanofluids in the flat tubes of a radiator, Int. J. Heat Fluid Flow 31 (2010) 613-621.

7. G. Huminic, A. Huminic, The cooling performances evaluation of nanofluids in a compact heat exchanger, SAE Tech. Pap. (2012), 2012-01-1045.

8. R.S. Vajjha, D.K. Das, D.R. Ray, Development of new correlations for the Nusselt number and the friction factor under the turbulent flow of nanofluids in flat tubes, Int. J. Heat Mass Transf. 80 (2014) 353-367.

9. G. Huminic, A. Huminic, Numerical analysis of laminar flow heat transfer of nanofluids in a flattened tube, Int. Commun. Heat Mass Transfer 44 (2013) 52-57.

10. P. Vivekh, D.T. Bui, M. Kumja, M.R. Islam, K.J. Chua, Theoretical performance analysis of silica gel and composite polymer desiccant coated heat exchangers based on a CFD approach, Energy conversion and management 187 (2019) 423 - 446.

11. Yuwen You, Hui Jiang, Jain Lv, Analysis of influence of IEC heat exchanger based on CFD method, Energy Procedia 158 (2019) 5759- 5764.

12. M.N. Pantzali, A.G. Kanaris, K.D. Antoniadis, A.A. Mouza, S.V. Paras, Effect of nanofluids on the performance of a miniature plate heat exchanger with a modulated surface, Int. J. Heat Fluid Flow. 30 (2009) 691 e699.

13. P. C. Mukesh Kumar, K. Palanisamy, J. Kumar, R. Tamilarasan, S. Sendhilnathan, CFD analysis of heat transfer and pressure drop in helically coiled heat exchangers using Al2O3 Journal of Mechanical Science and Technology 29 (2) (2015) 697-705.

14. R.V.M. Raja, S. Suresh, R. Vivekananthan, Effects of heat transfer enhancement and NOx emission using Al2O3/water Nano fluid as a coolant in CI engine, Indian J.Eng. Mater.Sci. 20 (October 2013) 7.

15. A.M. Hussein, R.A. Bakar, K. Kadirgama, K.V. Sharma, Heat transfer enhancement using Nano fluids in an automotive cooling system, Int.Commun. Heat Mass Transfer 53 (2014) 195-202. 
16. L. Asmaie, M. Haghshenasfard, A. Mehrabani-Zeinabad, M. Nasr Esfahany, Thermal performance analysis of Nano fluids in a thermosyphon heat pipe using CFD modelling, Heat Mass Transf. 49 (2013) 667-678 